In treating a case of retention, Dr. Dobie prefers, after having succeeded in insinuating the probe-pointed bougie through the stricture, to withdraw it, and afterwards attempt to pass a catheter. In common with all, or nearly all, surgeons, I deny that we can always do this. In a very difficult case, when an instrument is once through the stricture, surely it is safer to keep it there rather than to relinquish our success, and risk the hazard of a second trial; and then appears the advantage of having employed at the outset an instrument capable of emptying the bladder, instead of one which must be withdrawn and replaced by another before the patient can be relieved.

Lastly, one remark on Dr. Dobie's observation that I " make no very original statement" in affirming that the secret of success for extremely tight strictures is the use of a sufficiently small instrument, inasmuch as it "must be familiar to all readers of THE LANCET that Professor Syme has for many years held, and taught in the most emphatic manner, that that there are no strictures capable of allowing the passage of urine, even in drops, which cannot be permeated by skilfullydirected efforts with sufficiently small instruments."

The idea of claiming originality for that statement of mine is altogether Dr. Dobie's own. It was certainly never dreamed of by me. On the contrary, my object was mainly to confirm and corroborate that well-known view of Mr. Syme. Dr. Dobie may not be aware that I maintained its truth five years ago, * at a time when the opinions and practice of Mr. Syme in relation to stricture were far less generally accepted than they are at present-when, in fact, they encountered no little opposition here; and a larger experience has but more firmly impressed me with a sense of the practical value of a firm belief in the permeability of all urethral strictures-so much so, indeed, that the enunciation of that simple fact, I venture to think, is by no means one of the least of the many important truths which that distinguished surgeon has been the first to aemonstrate in connexion with the practice of our art. I am, Sir, your obedient servant,

HenRy Thompson, F.R.C.S., \&e.

Wimpole-street, Cavendish-square, July, 1857.

\section{A CASE OF INJURY TO THE SPINE.}

\section{To the Elditor of The LANCET.}

SIR,-Having read in the "Mirror," (The LANCET, June 13th,) a case of injury to the spine, under the care of $\mathrm{Mr}$. Lloyd at St. Bartholomew's Hospital, I feel induced to send you the particulars of a similar case, produced by a similar accident, which occurred in my own practice:-

Wm. S- a strong-built man, aged twenty-eight, labourer, whilst in a state of intoxication, on May 12th, slipped down a ladder, and struck the back of his neck against the steps. $\mathrm{He}$ was found by his master in a sitting posture, his head rest ing on the ladder; he placed him on some straw, and sent for me. The reason he did so was, that he found he had no use in his limbs. On my arrival, I found him very drunk, and com plaining of a great deal of pain in the back of his neck; was able to move his left arm up to the seat of pain, but lost all power as well as sensation in the right upper and both lowe extremities. He vomited a good deal; the skin was cold ; conscious as far as the drink would allow; pupils acted with the stimulus of light. I had him carefully removed to his home, and put to bed. As he was very drunk, I could not do much unti the effects of that had passed off, but merely ordered hot bottles of water to the extremities, and mustard poultices to the calves of his legs.

May 13th. - Half-past seven A.M.: Perfectly conscious, the effects of the drink having passed ofi; no head symptoms; complains of great pain in his neck, opposite the fifth and sixth cervical vertebræ; slight movement in his left hand; the remainder of the body paralyzed, as well as the loss of sensation below a line drawn from shoulder to shoulder; pulse 72; respiration 28 , and purely diaphragmatic. About two pints of highcoloured and offensive urine were drawn off. He can swallow and talk without any difficulty.-Six P.M.: Bowels have not acted; face very much flushed and puffed; quite conscious, and still complains of great pain in his neck; breathing shorter; palse 92 ; respiration 40 ; skin very hot; lost the little power of movement he had in his left hand.-Ten P.M.: Bowels have acted well; in other respects much the same. Urine drawn off.

14th. - Half-past seven A.m.: Has passed a restless night; the skin very hot, and face flushed; tongue dirty; pulse 84; respiration 36. A pint and a half of dark offensive urine drawn off ; complains of great pain between his shoulders. - Quarter to four: Pulse 80 ; respiration 40 ; in other respects the same. Ten P.M.: Dyspncea very much increased ; fancies he will be choked if I do not give him something to relieve it; constant emission of semen; his skin now perspires profusely; he is evidently sinking. He died at twenty minutes past twelve.

16th. - I obtained permission of his friends to examine the seat of injury, and found the fifth and sixth cervical vertebræ extensively fractured and comminuted, the spinal marrow being very much softened and inflamed opposite, above, and below the secut of injury to the extent of more than an inch. I remain, Sir, yours, \&c., Charles Francis Lewrs, M.R.C.S.L. Ledbury, Herefordshire, June, 1857.

\section{SAUSAGE-POISON.}

To the Editor of THE LANCET.

SrR,-The origin of the peculiar poison which has been found to exist in sausage-meat, has not, I believe, been hitherto satisfactorily accounted for by the chemists who have taken pains in its analysis; nor is it probable that chemical analysis; although it may determine the constitution of the poison itself, can account for an effect which is mainly physiological. The result of many experiments, upon which this opinion is based, I beg to submit to your candid consideration.

I have generally found that the admixture, and even contact, of the flesh of different animals have produced the poisonous property, and hastened decomposition in a remarkable manner, independently of the ordinary influences to which the latter effect is ascribable; and I have also observed that where sausage-meat has been prepared from a single portion of an individual animal, the virus has not appeared, and such rapid decomposition has not proceeded. The poison of sausages does not extend. to their putrefactive state, and cooking before the meat is minced seems to avert it altogether, which I account for by assuming the destruction of physiological distinctions in either process. I have, however, invariably noted that the substance of sausages is extremely liable to decomposition, even under the most favourable circumstances, the cause of which I attribute-

Firstly, to the comminution of the particles of meat-a process which is known to be the greatest accelerator of chemical decomposition;

Secondly, to the peculiar method adopted for making up sausages for use, which almost always brings parts of different animal bodies into contact, even where care has been taken to secure the individual character of the meat, the envelope used being seldom a portion of the original animal.

Any attempt to obviate the first-named cause would, of course, destroy the peculiar feature of our well-known viand. The best precaution appears to reside in a proper selection of material, and, if possible, not preparing it for use before it is required. The "sausage-skin" is a clumsy and pernicious expedient to secure the portability of mince-meat, and would, if rightly viewed, be repudiated by every person who had a palate to be offended and a stomach to be put out of order.

I cannot pretend to go deeper into this matter, but I trust that in competent hands the observations I have offered may lead to more elaborate experiments than mine. The sanitary importance of the subject is undoubtedly very great, and it is not improbable that investigation might be advantageously extended to the wholesome quality of other articles of diet in which the flesh of various animals is commingled to suit the taste of the epicure. - I am, Sir, yours obediently,

Andover-Flace, Kilburn, July, 1857.

F. B. Thompson.

\section{EXISTENCE OF THE OVA OF THE ACARUS SCABIEI IN ITCH.}

\section{To the Editor of THe LANOET.}

SIR, - In last week's number of The LaNCET, p. 7, is a paper by Dr. Gull, calling attention to the existence of the ova of the acarus scabiei in itch, and pointing out that the presence of these constitutes a diagnostic mark of that disease. Their existence, in certain cases of scabies, is a fact that has been long recognised; but it would be interesting to know whether they, or the acari themselves, can be discovered in all cases of itch. If this cannot be done, I do not think we are justified in assuming that the acarus is the sole cause of that disease, which is the opinion at present entertained. 
It may not, perhaps, be generally known to your readers, that after the re-discovery of this insect, and its demonstration to the savans of Paris by M. Renucci, in 1834, I was the first in this country to demonstrate its existence, and exhibited it, on several occasions, at microscopical soirées. A description of the appearance of the insect, its history, and the mode of finding it, may be seen in the 23rd volume of the Medical Gazette; where, also, is discussed the question, Is the acarns the sole cause of itch? In a subsequent paper, published in the same journal, I pointed out, what seemed to me, objections to this view, and expressed the opinion that there must be either different varieties of scabies, in one only of which, the $S$. Ver. micularis of Sanvages, was the acarus found, or that the disease was merely the nidus for the insect. These views seemed to be confirmed by some observations I afterwards made on the subject, and which, though not published at the time, I see no reason to withhold any longer from the profession.

Between Nov. 23rd, 1838, and Nov. 15th, 1839, I examined all the patients who were admitted into the foul wards of St. Bartholomew's Hospital, immediately after their admission, with the view of ascertaining how many of them were affected with scabies, and in what proportion of these the acarus existed. The results were as follows:- The total number of cases of scabies was 154; of which, 123 were females, and 31 males. The largest number occurred in the months of March and May; in each of which there were 25 patients affected : the smallest number was in December, when there were only 6 . From the total number, I have excluded 28 as doubtful, the skin being either scratched, scabby, or presenting the characters of that disease in an undefined manner, leaving 126 well marked and unmistakable cases of scabies: of these 126 cases, 100 were purely vesicular; 15 were both pustular and vesicular; and 11 pustular only. In the first, or vesicular form of scabies, 23 only exhibited traces of cuniculi; in the second, or pustulovesicular variety, acari were found in 7 , or nearly one-half; while in the third, or pustular form, none existed. Thus, in 126 cases of well-marked scabies, acari existed only in 30 , being less than one-fourth of the number. Two other facts, which point to the same conclusion, are the following:Firstly, acari have never been found in any other situation than at the extremity of a " cuniculus," and in none of the above cases were cuniculi discovered in any other locality than akout the hands and feet-mostly the former, rarely the latter. Secondly, no proportion was found to exist between the number of the " euniculi" and the intensity or diffusion of the eruption; the former might be numerous, and the latter very limited, or the whole body might bear evidences of the disease, and but a single " cuniculus" be discovered on a finger.

The argument of those who contend that if the acarus is not present, either the disease is not itch, or it has been previously treated, is disposed of by the fact, that none of the above cases had been subjected to any treatment before they were admitted into the hospital, and that all were cured by the sulphur ointment during their sojourn there.

I am, Sir, your obedient servant,

Storey's-gate, St. James's-park, $\quad$ C. Holthouse, F.R.C.S. July, 1857.

\section{POOR-LAW MEDICAL REFORM.}

THE SINGLE QUALIFICATION, AND MR. GRIFFIN. To the Editor of The Lancet.

SIR,-The cry Mr. Griffin is raising, and in which he is joined by certain diploma factors, against his professional brethren in the Poor-law service holding appointments with a single qualification, is to be regretted. He says, in his last "Annual Report," and again in his letter of June 20th, to the Poor-law Board, "I would not, on any account, disturb the present officers, but let it not go fortl to the world, that men not fully qualified for their duties are good enough for the poor, or that their lives are of less value than those of the rich." Mr. Griffin states that he does not wish the present officers disturbed; but should Parliament and the Poor-law Commissioners believe what he has written, it would not be in his power to prevent it.

Does Mr. Griffin really mean to tell us, that a man with a single qualification is incompetent to conduct a general practice? Has he overlooked the fact, that many of the best general practices in our towns and cities are carried on by men with a single qualification? Not one of the members of the council of the Royal College of Surgeons is in possession of the double qualitication. If all of them were (I wish they were) in the employment of boards of guardians, could it be fairly said it would be injurious to the poor and to the profession?

Mr. Griffin suggests, that " when a medical man, with only a single qualification, becomes doubly qualified, he should from that instant be a permanent officer." It would be absurd to make such an offer to a man with a family, hard pressed for time and money. Great would be the injustice and hardship done to those officers who, having, with credit to themselves, held appointments for many years, should they be deprived of them as soon as they are made a little more valuable, and other men introduced into the neighbourhood of their private practice, because they are in the possession of only the single qualification.

$M r$. Griffin states, that "plenty of men with a double. qualification can be found for the exigencies of the service were. but a fair remuneration offered." A man may have a double qualification and yet not be equal to the duties of a Poor-law medical officer. It is not a diploma and certificate that will always make him competent to "remove a limb above the knee, or excise an elbow-joint."

Just as the vexed question of qualification (with many others) is on the point of settlement, it would have been far better if Mr. Griffin had not written as he has of one class of his professional brethren. This unprofessional attack from him was little expected by them.

As regards the Poor-law Board, Mr. Griffin says, "Had the Poor-law Board insisted on the guardians carrying out Article 168 to the very letter, a finer staff of medical officers could not now have been in existence, and the title of Parish Doctor would not still be an opprobrium; but alas! a laxity has been permitted in this urder, as in most others." (See Report.) A careful inquiry, made by an impartial person, would show that the commissioners have not departed so much from the "articles in their order" as Mr. Griffin believes. The appointment of no one has been sanctioned by them who has not been "duly licensed to practise as a medical man," or qualified according to Article 168, 169, or 170. The Poor.law Board have not found it possible, in every locality, to give the appointments to men qualified according to either of the four modes mentioned in Article 168; nor could they do so at the present time, however much they might desire it, without inflicting great injury on the poor, who would have to go, in very many instances, much longer distances for medical advice than they do now.

It is a doubtful question, in point of law, whether the Commissioners have the power of compelling boards of guardians to give higher salaries to their medical officers. Some authorities say they have not. It is true a select committee of the House of Commons recommended it to the commissioners, and the commissioners recommended it to boards of guardians; but until Parliament give the commissioners more power, guardians will not be ruled by them in this matter.

Allow me to add a few words on Medical Reform and the Royal College of Surgeons. The Medical Reform agitation, which has been going on for nearly thirty years, with the confident expectation, year after year, that a Bill to amend the laws regulating the medical profession would be obtained, has been the cause of many men not getting the license of an apothecary, or something better. It is an undisputed fact, that the obstacles which, until very lately, have been placed in every step of the way of Medical Reform, emanated principally from the Council of the Royal College of Surgeons. Palmam qui meruit ferat.

July, 1857. I am, Sir, your obedient servant,

$$
\text { A Poon-law Medichl Officen. }
$$

\section{SCOTL A N D.}

\section{(FROM OUR EDINBURGH CORRESPONDENT.)}

TrE interest excited by the trial of Miss Smith for the alleged poisoning of M. Enile L'Angelier engrosses every other topic, and everything foreign to the subject is altogether disregarded or dismissed. Since the time of Palmer, perhaps no trial has been so dependent upon the medical evidence, and on this occasion, as on that, conflicting opinions are raised as to the action and effects of poison. Much, without doubt, rests against the young lady from the fact of her having purchased arsenic, for, as she affirms, the purposes of a cosmetic. Whether arsenic can with impunity be applied to the skin as a cosmetic is a point apparently, from the difference of opinion, difficult to determine. While Drs. Christison and Penny state its action to be violent and its results deleterious when used ex- 